\title{
Errors Associated with IV Infusions in Critical Care
}

\author{
Claudia Summa-Sorgini, Virginia Fernandes, Stephanie Lubchansky, Sangeeta Mehta, David Hallett, \\ Toni Bailie, Stephen E Lapinsky, and Lisa Burry
}

\begin{abstract}
Background: All medication errors are serious, but those associated with the IV route of administration often result in the most severe outcomes. According to the literature, IV medications are associated with $54 \%$ of potential adverse events, and $56 \%$ of medication errors.

Objectives: To determine the type and frequency of errors associated with prescribing, documenting, and administering IV infusions, and to also determine if a correlation exists between the incidence of errors and either the time of day (day versus night) or the day of the week (weekday versus weekend) in an academic medicosurgical intensive care unit without computerized order entry or documentation.
\end{abstract}

Methods: As part of a quality improvement initiative, a prospective, observational audit was conducted for all IV infusions administered to critically ill patients during 40 randomly selected shifts over a 7-month period in 2007. For each IV infusion, data were collected from 3 sources: direct observation of administration of the medication to the patient, the medication administration record, and the patient's medical chart. The primary outcome was the occurrence of any infusion-related errors, defined as any errors of omission or commission in the context of IV medication therapy that harmed or could have harmed the patient.

Results: It was determined that up to 21 separate errors might occur in association with a single dose of an IV medication. In total, 1882 IV infusions were evaluated, and 5641 errors were identified. Omissions or discrepancies related to documentation accounted for $92.7 \%$ of all errors. The most common errors identified via each of the 3 data sources were incomplete labelling of IV tubing (1779 or $31.5 \%$ of all errors), omission of infusion diluent from the medication administration record ( 474 or $8.4 \%$ of all errors), and discrepancy between the medication order as recorded in the patient's chart and the IV medication that was being infused ( 105 or $1.9 \%$ of all errors).

Conclusions: Strict definitions of errors and direct observation methods allowed identification of errors at every step of the medication administration process that was evaluated. Documentation discrepancies were the most prevalent type of errors in this paper-based system.

Key words: IV infusion, continuous infusion, errors, intensive care unit, critical care

Can J Hosp Pharm 2012;65(1):19-26

\section{RÉSUMÉ}

Contexte : Toutes les erreurs de médication sont sérieuses, mais celles impliquant la voie d'administration intraveineuse (i.v.) entraînent souvent les conséquences les plus graves. D'après la littérature, les médicaments i.v. sont associés à $54 \%$ des événements indésirables potentiels et à $56 \%$ des erreurs de médication.

Objectifs : Déterminer le type et la fréquence des erreurs associées à la prescription, à la consignation et à l'administration de perfusions i.v., et établir s'il existe une corrélation entre l'incidence des erreurs et le moment de la journée (jour ou nuit) ou le jour de la semaine (en semaine ou en fin de semaine) dans une unité de soins intensifs médicochirurgicaux universitaire non dotée d'un système informatisé de saisie des ordonnances et de consignation.

Méthodes : Dans le cadre d'un projet d'amélioration de la qualité, on a mené une vérification observationnelle prospective de toutes les perfusions i.v. administrées à des patients gravement malades, pendant 40 quarts de travail choisis au hasard au cours d'une période de sept mois en 2007. On a collecté des données sur chaque perfusion i.v. à partir de trois sources : l'observation directe de l'administration du médicament au patient, le registre d'administration des médicaments et le dossier médical du patient. Le principal paramètre d'évaluation était la survenue d'une erreur de perfusion, sans distinction du type. Une erreur de perfusion était définie comme toute erreur d'omission ou de commission dans le contexte de l'administration d'un médicament par voie i.v. qui a eu ou aurait pu avoir un effet délétère pour le patient.

Résultats : On a déterminé que jusquà 21 erreurs distinctes pouvaient survenir en association avec l'administration d'une seule dose de médicament par voie i.v. Un total de 1882 perfusions i.v. ont été évaluées et un total de 5641 erreurs ont été mises en évidence. Les omissions ou les divergences de consignation comptaient pour $92,8 \%$ de toutes les erreurs. Les erreurs les plus courantes dans chacune des trois sources étaient l'étiquetage incomplet de la tubulure i.v. (1779 ou 31,5\% de toutes les erreurs), l'omission d'inscription du diluant de la perfusion dans le registre d'administration des médicaments (474 ou 8,4\% de toutes les erreurs) et une divergence entre l'ordonnance telle qu' inscrite dans le dossier du patient et le médicament perfusé par voie i.v. (105 ou 1,9\% de toutes les erreurs).

Conclusions : Des définitions strictes des erreurs et des méthodes d'observation directe ont permis de mettre en évidence des erreurs à toutes les étapes du processus d'administration des médicaments qui ont été évaluées. Les divergences de consignation constituaient le type d'erreur le plus fréquent dans ce système non informatisé.

Mots clés : perfusion i.v., perfusion continue, erreurs, unité de soins intensifs, soins aux malades en phase critique

[Traduction par l'éditeur] 


\section{INTRODUCTION}

$\mathrm{T}$ The World Health Organization (WHO) has defined an adverse event as "an injury related to medical management, in contrast to complications of disease" and preventable adverse events as those "caused by an error or other type of systems or equipment failure". ${ }^{1}$ In 1999, the US Institute of Medicine highlighted the importance of preventable adverse events and patient safety, reporting that about 100000 people die each year in the United States as a result of medical errors. ${ }^{2}$ Medication errors have been documented as a major cause of preventable adverse events, which, in turn, are associated with substantial morbidity and mortality. ${ }^{3-9}$ Baker and others ${ }^{10}$ reported an overall incidence rate for adverse events of $7.5 \%$ in Canadian hospitals in 2000, and $36.9 \%$ of patients in that study were judged to have highly preventable adverse events, defined as events with a rating of 4 or more (i.e., more than a $50 \%$ likelihood that the error was caused by health care management) on a 6-point preventability scale. In the same study, the majority of adverse events (64.4\%) resulted in no physical impairment or disability or caused minimal to moderate impairment, with recovery within 6 months. However, $5.2 \%$ of the adverse events resulted in permanent impairment, and $20.8 \%$ resulted in death; $9 \%$ of the latter category of adverse events were judged to be highly preventable. ${ }^{10}$

In the intensive care unit (ICU), medication errors are the most common type of medical error, accounting for as many as $78 \%$ of serious medical errors. ${ }^{11}$ Frequent use of continuous infusions and high-risk medications, poor communication, complex orders, and repeated interruptions are among the factors associated with occurrence of errors in this setting. ${ }^{11}$ The process of administering medication to a patient can be subdivided into 5 phases (prescription, transcription, preparation, dispensing, and administration), and delivery of a single dose to an individual patient requires the correct execution of 80 to 200 individual steps. ${ }^{12-14}$ The complexity of the medication-use process, combined with high patient acuity and complexity of illness, makes medication administration in the ICU particularly prone to error. ${ }^{13}$ It has been estimated that critically ill patients experience 1.7 medication errors per day, and nearly all suffer a potentially life-threatening error at some point during their ICU stay. ${ }^{11,13,15,16}$

IV infusions form an integral component of the care of critically ill patients. The US Institute for Safe Medication Practices (ISMP) has reported that " $54 \%$ of potential adverse drug effects and $56 \%$ of medication errors are associated with IV medications". ${ }^{17}$ Fahimi and others ${ }^{18}$ reported that $66 \%$ of errors observed in their ICU were related to the administration of IV medications. Given that IV infusions in the ICU frequently involve high-risk medications such as insulin, vasopressors, sedatives, opioids, and concentrated electrolytes, concern about errors and adverse outcomes is warranted. ${ }^{17}$
A prospective observational study was conducted to determine errors associated with IV infusions in the medicosurgical ICU of the authors' institution. The objectives were to determine the incidence of errors, to characterize the types of errors that occurred, and to determine if there was a correlation between the incidence of errors and the time of day (day versus night) and day of the week (weekday versus weekend) when the errors occurred. The study was designed to provide baseline data for quality improvement initiatives.

\section{METHODS}

The Institutional Research Ethics Board approved the study, and the need for patient consent was waived because the study was related to a quality improvement initiative. Before initiation of the study, the ICU clinical staff, including nurses and physicians, were informed that a direct observational study would be conducted, that no staff identifiers would be collected (to ensure anonymity), and that a study observer would notify staff of any medication discrepancy identified in the course of the study.

\section{Setting}

The study was conducted in a 16-bed medicosurgical ICU of a 480-bed university-affiliated medical centre. The medical team consisted of specialized intensive care physicians, who rotated service weekly; ICU fellows and medical residents on 1 - to 2-month placements; 2 respiratory therapists per 12-h shift; and 1.0 full-time equivalent (FTE) dietitian and 0.8-FTE clinical pharmacist available during regular business hours (0800 to 1600). Nursing care was continuous, with a nurse-tobed ratio (a raw measure of workload) of 1:1. Full medical personnel present during regular business hours were 1 staff intensive care physician, 2 ICU fellows, 3 to 5 medical residents, and 1 or 2 medical students. Outside of regular business hours, 1 ICU fellow and 1 medical resident were on call on the premises, and 1 staff intensive care physician was on call remotely. Multidisciplinary patient care rounds were conducted daily between 0800 and 1300. All prescriptions were handwritten in the patient's chart, transcribed by a nurse, and sent by fax to the central pharmacy (which had hours of operation from 0730 to 2100 Monday to Friday and from 0800 to 1700 on Saturday and Sunday). Unit-dose distribution was used for oral therapies and for all IV medications with compounded stability of at least $24 \mathrm{~h}$. Nursing staff prepared IV medications with compounded stability less than $24 \mathrm{~h}$. Ward stock, night cupboard, and on-call services were available after hours. According to the availability of ward stock medications in the ICU and premixed formulations, as well as medications available after pharmacy hours, nursing staff may be required to prepare up to $65 \%$ of commonly ordered IV medications. 


\section{Observations}

Data were collected by direct observation during 40 randomly selected shifts (consisting of 10 weekday, 10 weeknight, 10 weekend-day, 10 weekend-night shifts) between January 2 and August 1, 2007. All patients admitted to the ICU during each observation period were included. The clinical team was not aware of the shifts during which data collection occurred. Errors were categorized in 4 groups, according to the shift during which they were observed (i.e., weekday, weeknight, weekend day, or weekend night). Day shifts were defined as 0730 to 1929 and night shifts as 1930 to 0729 , consistent with nursing shifts. To minimize the chance of data-collection shifts being too close together (e.g., Tuesday night and the following Wednesday morning), a ratio of 5:2 for weekday to weekend shifts was used in generating the data collection schedule. This allowed for data collection to take place 1 or 2 times per week. In addition, to minimize the chance of capturing the same error for the same patient more than once, the computer software generating the data collection periods was programmed to ensure that data-collection shifts were separated by at least $48 \mathrm{~h}$.

Four trained pharmacists (C.S.-S., L.B., V.F., T.B.) performed the data collection, using a standardized case report form to capture data during a 4-h time block within each observation shift. During the first 4 weeks of the study, one pharmacist supervised all data collection, to minimize interobserver variability. Each IV infusion bag was counted as a single dose, with data being collected from 3 separate sources: direct observation of the medication being administered to the patient (Section A, administration), the medication administration record (MAR) (Section B, documentation), and the patient's medical chart (Section C, prescription) (Figure 1). Data were captured in a particular sequence, to minimize observer bias. Specifically, data for section A (administration) was assessed without prior knowledge of information for sections B (documentation) and C (prescription).

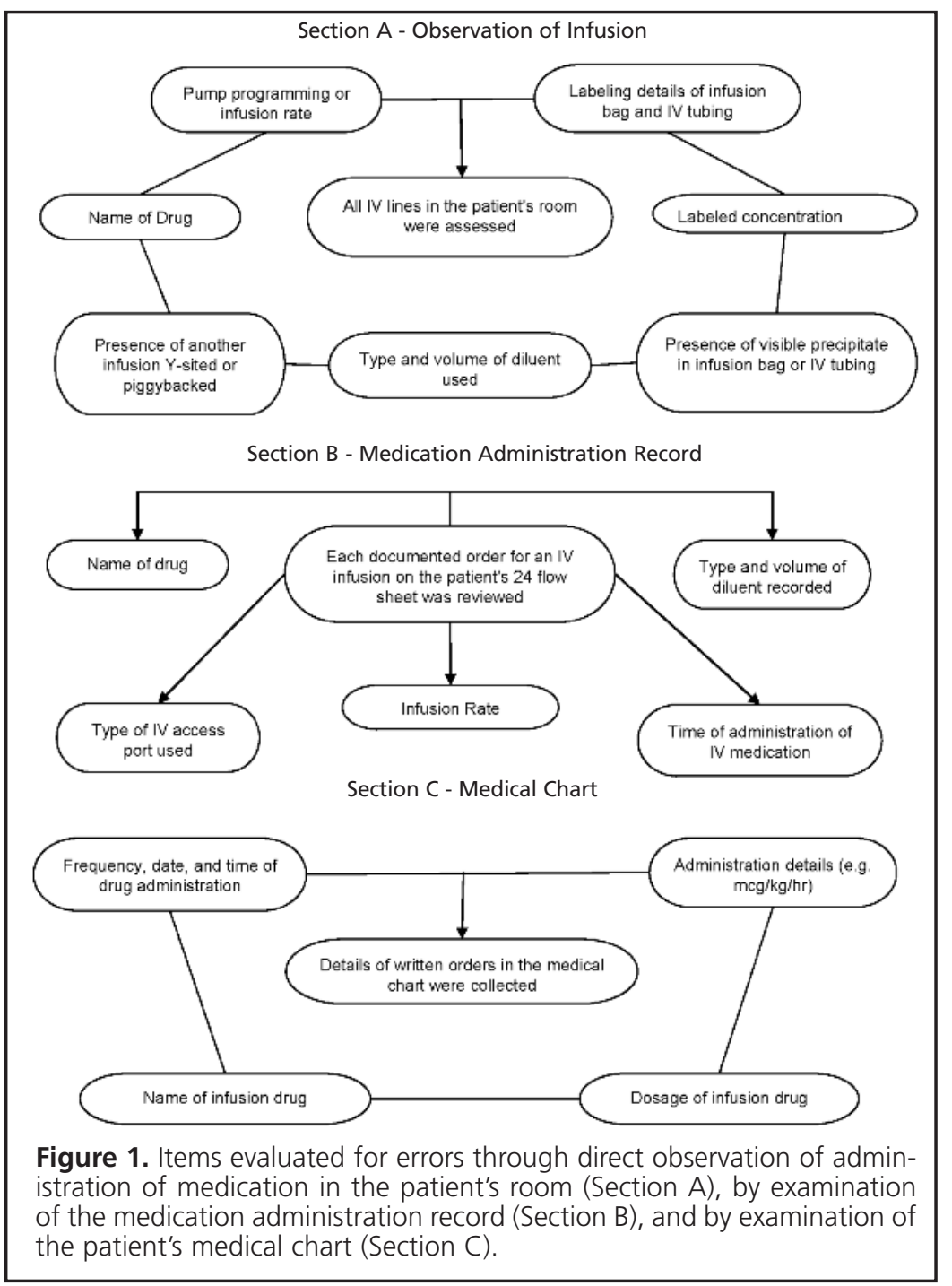




\section{Definitions and Evaluation of Incidents}

An infusion error was defined as any error of omission or commission in the context of IV drug therapy that harmed or could have harmed a patient. ${ }^{19}$ Definitions of errors were established a priori on the basis of the policies and practices at the study site (Table 1). The King Guide to Parenteral Admixtures, ${ }^{20}$ Trissel's Handbook of Injectable Drugs, ${ }^{21}$ the American Hospital Formulary System Drug Information database, ${ }^{22}$ and Micromedex (Drugdex System) ${ }^{23}$ were used to determine if the prescribed, documented, and administered infusions were appropriate.

\section{Data Analysis}

The primary outcome was the occurrence of errors. It was determined in advance that a possible 21 errors could be associated with a single dose of IV medication, according to site-specific medication administration systems, policies, and procedures. To determine the maximum number of potential errors during the study, the total number of possible errors for each infusion was multiplied by the number of infusions observed. The error frequency was reported as a percentage (actual number of errors $/ 21$ possible errors $\times$ no. of infusions $\times 100 \%)$ and as the mean number of errors per infusion. Data

\section{Table 1. Definition of Errors Associated with IV Infusions}

Type of Error

Section A: Administration (direct observation of medication being administered to patient)

Incomplete labelling of IV tubing

Incorrect labelling of IV tubing

Inappropriate Y-site or piggy-back

Inappropriate infusion rate

Inappropriate concentration

Inappropriate diluent

Inappropriate IV access

Incomplete or incorrect labelling of infusion bag
Tubing was labelled with only partial information (e.g., name of medication but no further details).

Labelling did not meet criteria that IV tubing be labelled with (1) type of medication being infused and (2) type of tubing (central or peripheral) at time of observation.

Products being infused together were not compatible or compatibility data to support the combination were lacking; precipitate was visible in infusion bag or IV tubing.

Infusion rate programmed on pump was not appropriate for the type of tubing being used.

Resulting concentration was inappropriate for the type of tubing being used. Type of solution used for dilution was inappropriate for type of IV access.

Given the type of medication and resultant concentration, tubing was not appropriate for medication administration.

Infusion bag was not labelled with the name of the medication, the concentration, and the date that the bag was prepared, or the bag was labelled incorrectly.

\section{Section B: Documentation (medication} administration record [MAR])

Concentration not recorded

Diluent not recorded

Infusion rate not recorded

Type of IV access not recorded

Medication not recorded

Incorrect tubing recorded

Incorrect diluent recorded

Incorrect infusion rate recorded

\section{Section C: Prescription}

\section{(patient's medical chart)}

Medication being infused but not ordered

Medication ordered but not being infused

Incorrect dose administered

Incorrect infusion rate only

Incorrect diluent
Concentration was not recorded in MAR.

Diluent was not recorded in MAR.

Infusion rate was not recorded in MAR.

Type of IV access was not recorded in MAR.

Infusion of medication was observed but not recorded in MAR.

Tubing recorded in MAR differed from tubing observed in patient's room.

Diluent recorded in MAR differed from diluent observed in patient's room.

Infusion rate recorded in MAR differed from infusion rate observed in patient's room.

Difference was identified between physician's orders and medication being infused.

Difference was identified between medication ordered by the physician and patient's therapy; specifically, medication ordered was not administered within the 4-h observation block (unless order specified otherwise).

Difference was identified between dose ordered by the physician and dose being infused.

Difference was identified between infusion rate ordered by the physician and infusion rate being used for administration.

Difference was identified between diluent ordered by the physician and diluent being used for infusion. 
are presented as percentages for categorical variables and as means with standard deviations (SDs) for continuous variables. Fisher's exact test was used to test for correlations between the time of shift (weekday, weeknight, weekend day, weekend night) and types of errors. A $p$ value of less than 0.05 was considered statistically significant.

\section{RESULTS}

A total of 180 patients, with demographic characteristics as described in Table 2, were present in the medicosurgical ICU during the 4-h time blocks of the 40 observation shifts. A single patient could be included more than once if he or she was admitted to the ICU during consecutive data-collection shifts or was readmitted to the ICU. A total of 1882 IV infusions were administered during the 4-h time blocks of the 40 randomly selected shifts. The maximum number of errors that could have resulted from these 1882 infusions was 39522 .

A total of 5641 errors of omission or commission were identified (14.3\% of the potential total of 39522$)$. The mean number of errors per infusion $( \pm S D)$ was $3.00 \pm 1.87$. In no cases was it necessary for the observer to intervene in patient care because of identification of an error that could have caused severe harm. Most of the errors identified related to incomplete or inaccurate documentation (5232 [92.7\%] of the 5641 errors). Overall, $62.9 \%$ of the errors were associated with administration of the medication to the patient (Section A), $34.3 \%$ were related to the MAR (Section B), and $2.7 \%$ were associated with the physician's written order in the patient's chart (Section C) (Table 3).

Errors were also categorized in relation to the time and day of the shift. More errors occurred during day shifts than night shifts (2759 versus 2064), and more errors occurred on weekdays than on weekends (3212 versus 1611 errors), but these differences were not statistically significant. Taking into account the 5:2 ratio of weekdays to weekends, the daily error frequency was 642 errors during weekdays (i.e., 3212 weekday errors/5 weekdays) and 806 errors during weekends (1611 weekend errors $/ 2$ weekend days), or a ratio of $44 \%$ to $56 \%$ (Table 4). Labelling discrepancies for the IV tubing were more commonly detected during day shifts than night shifts and during weekday shifts rather than weekend shifts (Table 4). As well, the concentration of medication in the IV infusion was less likely to be documented and observers were more likely to observe a medication being infused into the patient without an order in the patient's chart during weekday shifts. The type of IV access was less likely to be documented in the MAR during day shifts than during night shifts.

\section{DISCUSSION}

In this observational study, we evaluated errors associated with administering, documenting, and prescribing IV infusions in a closed medicosurgical academic ICU. The overall error rate was $14.3 \%$, and the mean number of errors per infusion was 3.00. Errors due to incorrect or incomplete documentation were the most prevalent type of error observed (92.7\%). These errors consisted primarily of inaccurate or incomplete labelling of IV infusion bags and/or IV tubing and inaccurate or incomplete documentation in the MAR. We can only speculate as to the clinical significance of these errors, but a lack of complete documentation could adversely affect clinical decision-making, thereby causing either inappropriate changes in therapy (e.g., dose adjustment, withholding of a dose, or administration of an additional dose) or clinician uncertainty about drug administration, especially during urgent situations (e.g., available IV line access or medications administered during cardiac arrest).

The detection of a high frequency of errors related to IV infusions is consistent with other studies. In a 2008 study to determine the incidence of errors during preparation and administration of IV medications, Fahimi and others ${ }^{18}$ observed a total of 380 errors out of the possible 4040 (9.4\%). In

Table 2. Characteristics of 180 Cases Included in the Study*

\begin{tabular}{lc}
$\begin{array}{l}\text { Characteristic } \\
\text { Mean } \pm \text { SD, No. (\%) of Patients, } \\
\text { or Median (IQR) }\end{array}$ \\
\hline Age (years) & $59.9 \pm 19.5$ \\
Sex, male & $86(48)$ \\
APACHE II score & $19.9 \pm 7.4$ \\
SOFA score & $8.6 \pm 4.3$ \\
Renal replacement therapy & $40(22)$ \\
Mechanical ventilation & $144(80)$ \\
Duration of mechanical ventilation (days) + & $4.5($ IQR 2.0-12.0) \\
No. of IV medications/patient per 4-h block & $3.8($ IQR $2.0-9.0)$ \\
\hline APACHE = Acute Physiology and Chronic Health Evaluation, IQR = interquartile range, \\
SD = standard deviation, SOFA = Sepsis-related Organ Failure Assessment. \\
*Individual patients may have been included in more than one study observation time \\
(i.e., may have been counted more than once). \\
tMean length of stay in the intensive care unit was 4.6 days.
\end{tabular}


Table 3. Summary of Errors Identified

\begin{tabular}{|c|c|c|c|}
\hline Type of Error & No. of Errors & $\%$ of Section & $\%$ of All Errors \\
\hline \multicolumn{4}{|l|}{$\begin{array}{l}\text { Section A: Administration (direct observation } \\
\text { of medication being administered to patient) }\end{array}$} \\
\hline Incomplete labelling of IV tubing & 1779 & 50.1 & 31.5 \\
\hline Incorrect labelling of IV tubing & 1509 & 42.5 & 26.8 \\
\hline Inappropriate Y-site or piggy-back & 239 & 6.7 & 4.2 \\
\hline Inappropriate infusion rate & 7 & 0.2 & 0.1 \\
\hline Inappropriate concentration & 3 & 0.08 & 0.05 \\
\hline Inappropriate diluent & 1 & 0.03 & 0.02 \\
\hline Inappropriate IV access & 0 & 0 & 0 \\
\hline Incomplete or incorrect labelling of infusion bag & 7 & 0.2 & 0.1 \\
\hline Other: bag hanging but not connected and/or medication not being infused & 5 & 0.1 & 0.09 \\
\hline Subtotal for direction observations & 3550 & 100 & 62.9 \\
\hline \multicolumn{4}{|l|}{$\begin{array}{l}\text { Section B: Documentation (medication } \\
\text { administration record [MAR]) }\end{array}$} \\
\hline Concentration not recorded & 470 & 24.3 & 8.3 \\
\hline Diluent not recorded & 474 & 24.5 & 8.4 \\
\hline Infusion rate not recorded & 374 & 19.3 & 6.6 \\
\hline Type of IV access not recorded & 430 & 22.2 & 7.6 \\
\hline Medication not recorded & 82 & 4.2 & 1.5 \\
\hline Discrepancy between MAR and direct observations* & 107 & 5.5 & 1.9 \\
\hline Subtotal for errors related to MAR & 1937 & 100 & 34.3 \\
\hline \multicolumn{4}{|l|}{ Section C: Prescription (patient's medical chart) } \\
\hline Medication being infused but not ordered & 38 & 24.7 & 0.7 \\
\hline Medication ordered but not being infused & 11 & 7.1 & 0.2 \\
\hline Discrepancy between direct observations and patient's chart $\dagger$ & 105 & 68.2 & 1.9 \\
\hline Subtotal for errors related to patient's medical chart & 154 & 100 & 2.7 \\
\hline Total (all errors) & 5641 & NA & 100 \\
\hline
\end{tabular}

\section{Table 4. Correlation of Errors with Time or Day of Shift}

Day versus Night

Type of Error

Incomplete labelling of IV tubing $(n=1779)$

Incorrect labelling of IV tubing $(n=1509)$

Concentration not recorded in MAR $(n=470)$

Type of IV access not recorded in MAR $(n=430)$

Infusion rate not recorded in MAR $(n=374)$

Discrepancy between MAR and direct observations ( $n=107)$

Medication ordered but not being infused $(n=11)$

Medication being infused but not ordered $(n=38)$

Discrepancy between direct observations and patient's chart $(n=105)$
Weekday versus Weekend

\begin{tabular}{lccccc} 
No. (\%) of Errors & $\boldsymbol{p}$ value & & No. (\%) of Errors & p value \\
\hline $993(56)$ vs. $786(44)$ & 0.001 & & $1170(66)$ vs. $609(34)$ & $<0.0001$ \\
$857(57)$ vs. $652(43)$ & $>0.99$ & & $983(65)$ vs. $526(35)$ & 0.28 \\
$267(57)$ vs. $203(43)$ & 0.21 & & $325(69)$ vs. $145(31)$ & 0.05 \\
$257(60)$ vs. $173(40)$ & 0.02 & & $289(67)$ vs. $141(33)$ & 0.85 \\
$212(57)$ vs. $162(43)$ & 0.48 & & $263(70)$ vs. $111(30)$ & 0.12 \\
$65(61)$ vs. $42(39)$ & 0.27 & & $79(74)$ vs. $28(26)$ & 0.11 \\
$7(64)$ vs. $4(36)$ & $>0.99$ & & $5(45)$ vs. $6(55)$ & 0.41 \\
$30(79)$ vs. $8(21)$ & $>0.99$ & & $26(68)$ vs. $12(32)$ & 0.04 \\
$71(68)$ vs. $34(32)$ & 0.08 & & $72(69)$ vs. $33(31)$ & 0.52
\end{tabular}

MAR = medication administration record. 
contrast to the findings reported here, the majority of the errors in the earlier study were related to bolus administration $(43.4 \%)$ and incorrect infusion rate $(23.0 \%)$. Although bolus infusions were not analyzed separately in the current study, infusion rate errors accounted for $7(0.2 \%)$ of 3550 errors associated with administration of the medication to the patient (Section A) and 397 (20.5\%) of 1937 errors related to the MAR (Section B). In addition, 37 (24.0\%) of 154 Section C errors (discrepancies between prescription and observed administration) were related to the infusion rate. Flaatten and Hevrøy ${ }^{24}$ found that $17(19.5 \%)$ of 87 errors were associated with IV infusion, primarily incorrect infusion (6.9\%) and incorrect concentration (3.4\%). Differences in error frequencies between studies may be attributable to differences in study methods and differences in site-specific practices and resources, such as the hours of service for pharmacy IV admixture programs and the use of computer order entry and bar-coding. In the study reported here, compatibility and administration errors were not as common as in previous studies, but documentation errors were more frequent. One possible explanation for these findings is the high availability at the study institution of resources to support the ICU team when compounding and administering IV therapies (e.g., compatibility and bedside IV dosing charts, institutional guidelines for IV administration of medications). The patient population also plays an important role in the incidence of medication errors, as patients with greater severity of illness are more likely to have a greater number of medications prepared and administered and are more likely to experience a longer stay in hospital, all of which result in a higher risk of error. ${ }^{18}$

Differences in the frequency of errors during day and night shifts have been reported, with errors being more frequent during morning hours (particularly around 0900) than in the afternoon or at night. ${ }^{18}$ We hypothesized that there would be significant differences in the frequency of errors between day and night, as well as between weekdays and weekends, but our data did not support this hypothesis. However, with regard to errors of incomplete labelling, we detected a significantly higher frequency during the day versus the night, and a higher frequency on weekdays versus weekends. The higher rate of daytime errors may be attributable to the high prescribing rate during the daytime, as well as greater numbers of procedures and visits from consultants and family members, which may be associated with more interruptions in nursing work flow. At night, staff may be able to take more time to complete each task, ensuring greater accuracy and precision.

The strengths of this study include its prospective design, the equal sampling of all time periods according to randomized observation blocks, the large number of IV infusions evaluated, and the detailed data collection. The study also had several limitations. First, ICU staff were aware of the activities being evaluated, which might have influenced (i.e., artificially increased or decreased) the observed error rate. Second, we did not capture data on errors associated with preparing the IV medications (e.g., incorrect medication vial chosen from floor stock, reconstitution errors). Thus, when observers were documenting errors in a patient's room, it was assumed that the medication being infused, with labelling by nurses, was indeed that indicated on the label on the infusion bag. Interestingly, other researchers, including Parshuram and others, ${ }^{16}$ have found significant errors associated with compounding in a critical care setting. We did not capture data about the prescription-writing process and thus are unable to conclude whether the medication order reflected the physician's intentions. Also, we were unable to assess the severity or grading of the errors. Finally, our findings may not be generalizable to ICUs with different patient populations, staffing models, or processes of delivering medications (e.g., 24-h pharmacy compounding services), or those with computerized order entry.

\section{CONCLUSIONS}

Preventing medication errors should always be an important part of patient care. In the past, practice audits have focused on medication errors and adverse drug events in general, not on errors associated with IV administration of medications. The few published audits have reported medication errors for about $50 \%$ of all instances of IV administration of medications.

The information obtained from this prospective study has helped to guide the study institution's subsequent quality improvement strategies. For example, the institution has increased the correctness and completeness of labelling for IV infusions by increasing the number of IV infusions prepared by the pharmacy and the use of premixed labelled solutions, which means that fewer infusions are prepared at the patient's bedside. In addition, the pharmacy provides preprinted labels to be affixed to the infusion bag for low-stability infusions prepared in ICU. We plan to assess the errors associated with IV infusions in the ICU as we implement computerized physician order entry, electronic MARs, bar-coding, and smart pump technology.

\section{References}

1. World Alliance for Patient Safety. WHO draft guidelines for adverse event reporting and learning systems: from information to action. Geneva (Switzerland): World Health Organization; 2005 [cited 2012 Jan 11]. Available from: www.who.int/patientsafety/events/05/Reporting_Guidelines.pdf

2. Kohn LT, Corrigan, Donaldson MS. To err is human: building a safer health system. Washington (DC): National Academy Press; 2000.

3. Pronovost PJ, Thompson DA, Holzmueller CG, Lubomski LH, Morlock LL. Defining and measuring patient safety. Crit Care Clin 2005;21(1):1-19, vii.

4. Rothschild JM, Landrigan CP, Cronin JW, Kaushal R, Lockley SW, Burdick E, et al. The Critical Care Safety Study: the incidence and nature of adverse events and serious medical errors in intensive care. Crit Care Med 2005;33(8):1694-1700. 
5. Apkon M, Leonard J, Probst L, De Lizio L, Vitale R. Design of a safer approach to intravenous drug infusions: failure mode effects analysis. Qual Saf Health Care 2004;13(4):265-271.

6. van den Bemt PMLA, Fijn R, van der Voort PHJ, Gossen AA, Egberts TC, Brouwers JR. Frequency and determinants of drug administration errors in the intensive care unit. Crit Care Med 2002;30(4):846-850.

7. Infusion pumps - opportunities for improvement. ISMP Can Saf Bull 2003;3(7):1-2. Available from: www.ismp-canada.org/download/ safetyBulletins/ISMPCSB2003-07InfusionPumps.pdf

8. NCC MERP: the first ten years. Defining the problem and developing solutions. National Coordinating Council on Medication Error Reporting and Prevention; 2005 Dec [cited 2012 Jan 11]. Available from: www.nccmerp.org/pdf/reportFinal2005-11-29.pdf

9. Vincent JL, Moreno R, Takata J, Willatts S, De Mendonça A, Bruining H, et al.; Working Group on Sepsis-Related Problems of the European Society of Intensive Care Medicine. The SOFA (Sepsis-related Organ Failure Assessment) score to describe organ dysfunction/failure. Intensive Care Med 1996;22(7):707-710.

10. Baker GR, Norton PG, Flintoft V, Blais R, Brown A, Cox J, et al. The Canadian Adverse Events Study: the incidence of adverse events among hospital patients in Canada. CMAJ 2004;170(11):1678-1686.

11. Herout PM, Erstad BL. Medication errors involving continuously infused medications in a surgical intensive care unit. Crit Care Med 2004; 32(2):428-432.

12. Gikic M, DiPaolo ER, Pannatier A, Cotting J. Evaluation of physiochemical incompatibilities during parenteral drug administration in a pediatric intensive care unit. Pharm World Sci 2000;22(3):88-91

13. Tissot E, Cornette C, Demoly P, Jacquet M, Barale F, Capellier G. Medication errors at the administration stage in an intensive care unit. Intensive Care Med 1999;2(4):353-359.

14. Cohen M. Medication errors. 2nd ed. Washington (DC): American Pharmacists Association; 2007.

15. Calabrese AD, Erstad BL, Brandl K, Barletta JF, Kane SL, Sherman DS Medication administration errors in adult patients in the ICU. Intensive Care Med 2001;27:1592-1598.

16. Parshuram CS, Ng GY, Ho TK, Klein J, Moore AM, Bohn D, et al. Discrepancies between ordered and delivered concentrations of opiate infusions in critical care. Crit Care Med 2003;31:2483-2487.

17. Pharmacy-nursing shared vision for safe medication use in hospitals: executive summary session. Am J Health Syst Pharm 2003;60(10):1046-1052.

18. Fahimi F, Ariapanah P, Faizi M, Shafaghi B, Namdar R, Ardakani MT. Errors in preparation and administration of intravenous medications in the intensive care unit of a teaching hospital: an observational study. Aust Crit Care 2008;21(2):110-116.

19. American Society of Hospital Pharmacists. ASHP guidelines on preventing medication errors in hospitals. Am J Hosp Pharm 1993;50(2):305-314.
20. Catania P, editor. King guide to parenteral admixtures. Stockton: Patrick N. Catania; 2007.

21. Trissel LA. Handbook on injectable drugs. 14th ed. Bethesda (MD): American Society of Health-System Pharmacists; 2007.

22. McEvoy GK, editor. AHFS drug information 2007. Bethesda (MD): American Society of Health-System Pharmacists; 2007.

23. Micromedex, Drugdex System ${ }^{\circledR}$ [database]. New York (NY): Thomson Healthcare [cited 2007 Jan]. Available from: www.thomsonhc.com

24. Flaatten $\mathrm{H}$, Hevrøy O. Errors in the intensive care unit (ICU): experiences with an anonymous registration. Acta Anaesthesiol Scand 1999;43(6): 614-617.

Claudia Summa-Sorgini, BSCPharm, ACPR, was, at the time this study was conducted, a pharmacy resident at Mount Sinai Hospital, Toronto, Ontario. She is now a Clinical Pharmacist with the University Health Network, Toronto, Ontario.

Virginia Fernandes, BSC (Hon), PharmD, is a Clinical Pharmacist at Mount Sinai Hospital, Toronto, Ontario.

Stephanie Lubchansky, BSc, is a Research Assistant at Mount Sinai Hospital, Toronto, Ontario.

Sangeeta Mehta, MD, FRCPC, is ICU Research Director, Mount Sina Hospital, Toronto, Ontario.

David Hallett, BSC, MSC, was, at the time this study was conducted, the statistician for the intensive care unit at Mount Sinai Hospital, Toronto, Ontario. He is now a statistician with Cancer Care Ontario, Toronto, Ontario.

Toni Bailie, BScPharm, is a Clinical Pharmacist at Mount Sinai Hospital, Toronto, Ontario.

Stephen E Lapinsky, MD, FRCPC, is ICU Director, Mount Sinai Hospital, Toronto, Ontario.

Lisa Burry, BScPharm, PharmD, FCCP, is a Clinical Pharmacy Specialist at Mount Sinai Hospital, Toronto, Ontario.

\section{Address correspondence to:}

Dr Lisa Burry

Room 1504

Mount Sinai Hospital

600 University Ave

Toronto ON M5G 1X5

e-mail: Iburry@mtsinai.on.ca 